Proceedings of the 11th Polish-Japanese Joint Seminar on Micro and Nano Analysis, Gniew, September 11-14, 2016

\title{
Fatigue Characteristics of Laser Welded DC06EK and DP600MC Steel Sheets
}

\author{
M. Mihaliková, A. Lišková*, M. Hagarová and J. Cervová \\ Department of Materials Science, Faculty of Metallurgy, Technical University of Košice, \\ Letná 9, 04200 Košice, Slovakia
}

\begin{abstract}
Welding of different types of steel is fundamental proces for the production of car bodies. Fatigue degradation is still a significant factor in long-term use. Current trends welding and combinations of different types of steel are used. The specific form of the course of fatigue in the welded joints is followed. Test samples loaded fatigue tests, microscopic and scanning electron microscopy analysis of welded joints of steel type IF (DC06EK) and DP (DP600MC) are done. The resulting values of endurance tests are graphically processed by the Wöhler curve.
\end{abstract}

DOI: 10.12693/APhysPolA.131.1347

PACS/topics: automotive steel, laser welding, fatigue, microhardness

\section{Introduction}

Selection of a material for car body components is an activity that involves a number of areas. These have a considerable impact on overall fuel economy, the ecology, drive ability, and not least on the safety [1].

Dual-phase steels are among the most important materials of automotive engineering. Dual-phase steel is a high-strength steel that has a ferrite and martensitic microstructure [2-6]. Microstructure is consisting of a soft ferrite matrix containing islands of martensite as the secondary phase (martensite increases the tensile strength). Formability allows the production of thin and strong components for many applications in vehicles [7, 8].

IF steels were designed to provide an excellent combination of drawability and mechanical strength. IF steel has ultra-low carbon content, achieved by removing carbon monoxide, hydrogen, nitrogen, and other gasses during steelmaking through a vacuum degassing process. Interstitial elements like nitrogen or carbon are also in the form of nitrides and carbides due to the alloying elements such as $\mathrm{Nb}$ and/or $\mathrm{Ti}$ used for the stabilization of the residual interstitials [9]. Interstitial free steel are used for ultra-deep drawing [10].

Laser beam welding (LBW) is a welding technique used to join multiple pieces of metal through the use of a laser. The beam provides a concentrated heat source, allowing for narrow, deep welds and high welding rates. The process is frequently used in high volume applications, such as in the automotive industry. It is based on keyhole or penetration mode welding [11-16].

The aim of this paper is to investigate properties of laser welded DP600MC- DC06EK steel in cyclic loading conditions.

*corresponding author; e-mail: anna.liskova@tuke.sk

\section{Experimental materials and methods}

The experimental materials were laser-welded DC06EK and DP600MC steel. The chemical composition is shown in Table I. The experimental materials were supplied in the form of thin sheets with a thickness of $1.97 \mathrm{~mm}$. Welding parameters were as follows: laser power $2 \mathrm{~kW}$, welding speed $2 \mathrm{~mm} / \mathrm{s}$, feeding fibre diameter $100 \mu \mathrm{m}$, collimation $110 \mathrm{~mm}$, focal length $200 \mathrm{~mm}$, focal point position $190 \mathrm{~mm}$.

TABLE I

Chemical composition (in \%) of experimental materials (Fe - balance).

\begin{tabular}{|c|c|c|c|c|c|c|c|c|c|c}
\hline Mat. & $\mathrm{C}$ & $\mathrm{S}$ & $\mathrm{N}$ & $\mathrm{Mn}$ & $\mathrm{P}$ & $\mathrm{Si}$ & $\mathrm{Al}$ & $\mathrm{Ni}$ & $\mathrm{V}$ & $\mathrm{Ti}$ \\
\hline
\end{tabular}

\begin{tabular}{l|l|l|l|l|l|l|l|l|l|l|l|}
\hline DC06EK & 0.001 & 0.0105 & 0.0017 & 0.082 & 0.011 & 0.006 & 0.055 & 0.013 & 0.002 & 0.040 \\
\hline
\end{tabular}

\begin{tabular}{l|l|l|l|l|l|l|l|l|l|l|l}
\hline $\mathrm{DP} 600 \mathrm{MC}$ & 0.072 & 0.006 & 0.005 & 1.180 & 0.017 & 0.01 & 0.057 & 0.002 & 0.003 & 0.001
\end{tabular}

Effect of chemical composition on weldability of selected types of steel can be described as carbon equivalent $C_{E}$ according to Eq. (1) [17]:

$$
C_{E}=\mathrm{C}+\frac{\mathrm{Mn}}{6}+\frac{\mathrm{Cu}+\mathrm{Ni}}{15}+\frac{\mathrm{Cr}+\mathrm{Mo}+\mathrm{V}}{5} .
$$

\section{Microstructure}

The specimens for microstructural studies were mechanically polished using standard metallographic procedures and etched with a 4 vol. $\%$ nital solution and observed using a SEM (JEOL JSM-7000F) optical microscope.

\section{Microhardness}

The test was performed using Microhardness Struers - Duramin 5. In the material under test there was a diamond pyramid indentation with a load of $0.98 \mathrm{~N}$ and hold for $5 \mathrm{~s}$. Micro hardness test was performed in accordance with ISO/DIS 6507-1 [18]. Test surface was modified before measurement of micro-hardness standard metallographic procedures. The distance between punctures was $0.15 \mathrm{~mm}$. Microhardness measurements were carried out for metallographic sample through the weld seam of three lines. 


\section{Fatigue measurement}

Fatigue tests of welded joints in steel DC06EK and DP600MC were carried out according to STN 42 0363 [19]. Fatigue was implemented in conditions of cyclic loading on an Instron 8511 machine with a load frequency of $25 \mathrm{~Hz}$ at constant oscillation asymmetry coefficient $0<R<1$. Reflection electron microscope (REM) analysis was performed using scanning electron microscopy JEOL JSM 7000 F.

\section{Discussion}

From Eq. (1) carbon equivalents for steels were calculated: DC06EK $=0.01623$ wt\%, $\mathrm{DP} 600 \mathrm{MC}=0.2694 \mathrm{wt} \%$. All steel used satisfies the requirements $C_{E} \leq 0.45 \mathrm{wt} \%$ [17].

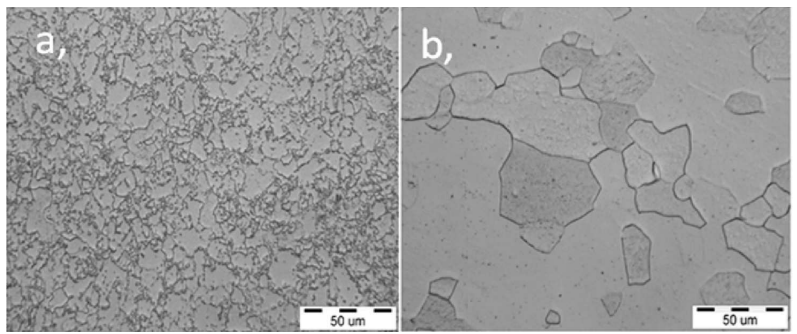

Fig. 1. Microstructures of basic material: DP600MC and (b) DC06EK steel.

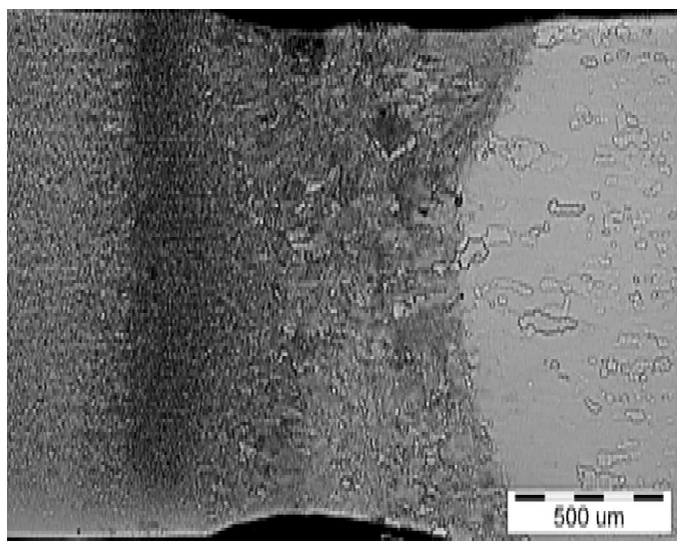

Fig. 2. Microstructure of the weld joint.

DP600MC steel microstructure is ferritic-martensitic containing about $10 \%$ martensite and the size of ferritic grains $\approx 6 \mu \mathrm{m}$. In Fig. 1b the size of ferritic grains is $\approx 20 \mu \mathrm{m}$. The microstructure of the weld joint is shown in Fig. 2. The detail of the microstructure of weld metal (WM) is shown in Fig. 3. The microstructure of weld metal is the bainite and acicular ferrite.

Figure 4a shows the weld and the heat-affected zone (HAZ) of the DP600MC steel. Microstructure of heataffected zone on the side of DP600MC steel are martensite, tempered martensite, bainite, ferrite and side plate ferrite (Fig. 5) [20]. Figure 4b shows a part of the weld and HAZ - DC06EK steel. Microstructure of heataffected zone on the side of DC06EK steel shows enlargement of ferritic grains $\approx 130 \mu \mathrm{m}$. The growth of the



Fig. 3. The detail of the microstructure of WM.



Fig. 4. HAZ microstructure (a) DP600MC steels, (b) DC06EK steels.

DC06EK steel ferritic grains occurs, because the grains of the complete $\alpha \rightarrow \gamma$ transformation are not balanced. Many of the results published in the literature [21-23] suggest that excessive grain growth is essentially due to recrystallization in the ferrite phase at temperatures below $A_{c_{1}}$. The second hypothesis is that excessive grain size is due to the $\gamma \rightarrow \alpha$ transformation under a thermal gradient. Firstly, a bainitic ferrite like structure in the



Fig. 5. SEM micrographs DP600MC: (a) DP600MC base metal, (b) HAZ - DP600MC steels, (c) fusion zone [20]. 
form of equiaxed grains is seen at the centre, which corresponds to a zone. Secondly, the grain size is finer when approaching the grips. Finally, highly elongated grains are observed just in the vicinity of the HAZ on the side base material DC06EK steel sheet. The grain size in this zone corresponds to those observed regularly in certain grades of DC06EK steel welds [21]. These results suggest that the temperature of the zone of maximum grain growth corresponds well to the temperature range of the $A_{c 3}-A_{c 1}$ of the grades of DC06EK steel during the cooling stage $(\gamma \rightarrow \alpha$ transformation). In these conditions, it was not possible to obtain a significant grain growth compared to that observed for welds. This suggests the major role of the thermal gradient on the excessive grain growth [21]. The growth rate of the grains depends on the chemical composition and the intensity of the effect of heat.

The overall impact of manganese on microstructure shows gradual increases of the amount of acicular ferrite, at the expense of pro-eutectoid ferrite and lamellar intermediate component. In addition, the needle-like ferrite, themselves, becomes progressively finer on the side base material DP steel [24]. During the conversion $\alpha \rightarrow \gamma$ at DP steel occurs the formation of precipitates, nitride and carbide type (AlN, TiC, or interphase precipitates $\mathrm{NbC}$ ). These precipitates effectively inhibit the growth of $\gamma$-grains. Enlargement of grains in this area is not as visible as in the case of DC06EK steel [20]. Profile of laser welded steel microstructure DP600MC connection is shown in Fig. 5, which corresponds directly to the microstructural changes according to the literature [25].

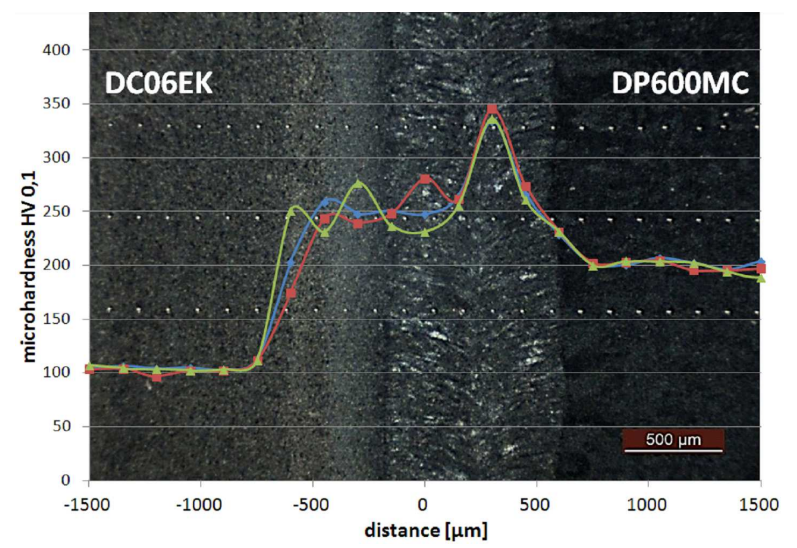

Fig. 6. Course microhardness weld joint DC06EK and DP600MC steels.

Microhardness was measured with tester Hanemann, type Mod D32. The microhardness in the heat affected area on the side of DC06EK steel is not significant. This can be explained by the fact that there was only an increase of ferritic grains and microhardness began to rise up the interface of heat affected zone and weld metal. The microhardness of the weld metal reached more than double value due to the appearance of bainite in the structure of the weld metal. Figure 6 shows cross weld microhardness profile of DP600MC and DC06EK laser



Fig. 7. Wöhler curve of welded joints.

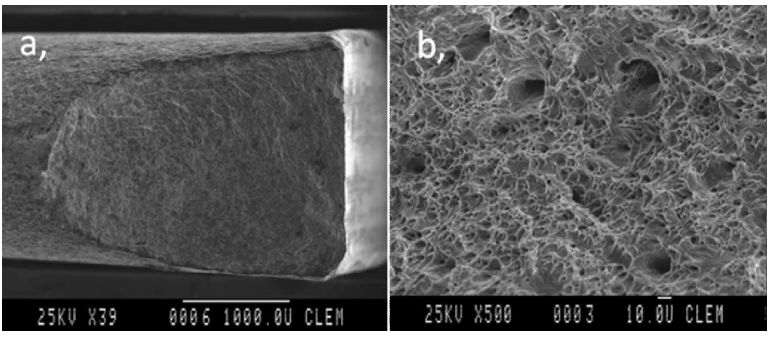

Fig. 8. Fracture surfaces in HAZ: (a) after fatigue test, (b) morphology of fracture surfaces after fatigue test.

welded steel sheets.

Figure 7 shows the Wöhler curve, constructed from the data obtained after the fatigue test. Value of the maximum stress of fatigue is $260 \mathrm{MPa}$. Ferritic grains in weld metal decreased fatigue life. Fatigue fracture area showed as planar with mixed fracture morphology. It was determined by detailed micro-fractographical observation that fracture area was formed by mechanism of trans-crystalline ductile failure with morphology of various pits (Fig. 8a,b). Typical signs of failure fractures in low-cycle fatigue conditions include tyre tracks and diagonal cracks.

\section{Conclusion}

This paper reports the mechanical and fatigue properties of DC06EK and DP600MC automotive steel sheets. Following conclusions can be concluded from the obtained results:

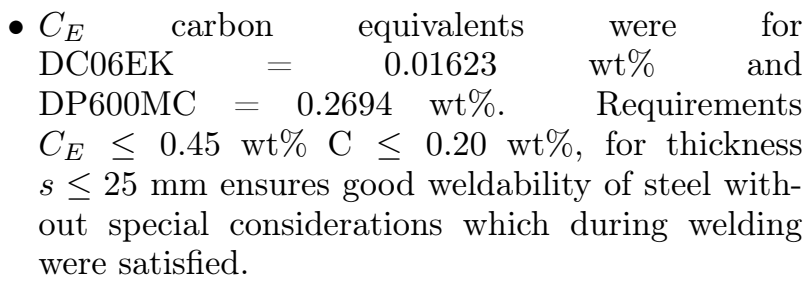

- Microhardness of welded joints DC06EKDP600MC steels was 2.5 times higher compared to the base material. Lowest microhardness welded joints was on side HAZ DC06EK steel. This area was considered as critical area of the weld joint. 
- In the conditions of cyclic loading there was determined value of the maximum stress of fatigue as $260 \mathrm{MPa}$.

- The microstructure of the weld joint consisted of bainite and acicular ferrite.

- Fatigue fracture surface morphology was characterized by mixed-infringement, transcrystalline fracture, pit, and intracrystalline fracture morphology with smooth surface.

\section{Acknowledgments}

This study was supported by the Grant Agency of Slovak Republic, grant project VEGA 1/0549/14.

\section{References}

[1] V. Girman, V. Hrabčáková, Mater. Engineer 2012, (2012).

[2] B. Demir, B.-M. Erdogan, J. Mater. Process. Technol. 208, 1 (2008).

[3] S. Oliver, T.B. Jones, G. Fourlaris, Mater. Character. 58, 4 (2007).

[4] M. Sarwar, R. Priestner, J. Mater. Eng. Perform. 8 , 3 (1999).

[5] H. Huh, S.B. Kim, J.-H. Song, J.-H. Lim, Int. J. Mech. Sci. 50, 918 (2008).

[6] J. Memg, P. Zhu, Z.G. Hu, Adv. Mater. Res. 139141, 205 (2010).

[7] M.G. Lee, D.Y. Kim, C.M. Kim, M.L. Wenner, R.H. Wagoner, K.S. Chung, Int. J. Plastic. 21, 883 (2005).
[8] S.B. Kim, H. Huh, H.H. Bok, M.B. Moon, J. Mater. Process. Technol. 211, 851 (2011).

[9] A. Momeni, K. Dehghani, S. Abbasi, M. Torkan, J. Metall., J. Metall. 13, 131 (2007).

[10] N. Kamikawa, N. Tsuji, Y. Minamino, Sci. Technol. Adv. Mater. 5, 163 (2004).

[11] S.I. Kim, S.H. Choi, Y.C. Yoo, Mater. Sci. Forum 495-497, 537 (2005).

[12] P. Zimovčak, O. Milkovič, P. Zubko, M. Vojtko, Chemické listy 105, s223 (2011).

[13] S. Katayama, Y. Kawahito, M. Mizutami, Phys. Proced. 39, 8 (2012).

[14] M. Zhang, G. Chen, Y. Zhou, S.C. Li, Opt. Express 21, 19997 (2013).

[15] M. Azadeh, Fiber Optics Engineering, Springer, New York 2009, p. 94.

[16] Ch. Dawes, Laser Welding: A Practice Guide, Abington Publ., Cambridge 1992.

[17] L. Kaščak, E. Spišák, I. Gajsoš, Key Eng. Mater. 635, 143 (2015).

[18] M. Mihaliková, L. Ambriško, L. Pešek, Kovov. Mater. 49, 137 (2011).

[19] J. Viňáš, M. Ábel, Mater. Sci. Forum 818, 239 (2015).

[20] J.M. Rodriguez-Ibabe, Mater. Sci. Forum 284-286, 51 (1998).

[21] D.O. Wilshynky-Dresler, D.K. Matlock, G. Krauss, in: Conf. Proc. ISIJ, Tokyo, 1994, p. 13.

[22] Conf. Proc. CANMET, Canada, 1991, Eds. C. Galvani, D. Baragar, L.E. Collins, D. Baragar, p. 119.

[23] Y.B. Park, H.J. Kang, S.K. Chang, in: Conf. Proc. ISIJ, Tokyo, 1994, p. 245.

[24] G.M. Evans, Suppl. Welding J. 59, 67 (1980).

[25] N. Farabi, D.L. Chen, Y. Zhou, J. Alloys Comp. 509, $982(2011)$. 